\title{
Bronchoconstriction induced by inhaled adenosine 5'-monophosphate in subjects with allergic rhinitis
}

\author{
L. Prieto, V. Gutiérrez, J. Liñana, J. Marín
}

\begin{abstract}
Bronchoconstriction induced by inhaled adenosine 5'-monophosphate in subjects with allergic rhinitis. L. Prieto, V. Gutiérrez, J. Liñana, J. Marín. (C) ERS Journals Ltd 2001. ABSTRACT: Adenosine and its related nucleotide, adenosine 5'-monophosphate (AMP) induce bronchoconstriction in asthmatics, probably caused by histamine release from airway mast cells. The objective of this study was to determine the effect of inhaled AMP on lung function in subjects with allergic rhinitis.

A total of 52 adults (28 subjects with allergic rhinitis, 14 asthmatics and 10 healthy subjects) were challenged with increasing concentrations of AMP and methacholine. Airflow was assessed after each concentration and the response to each bronchoconstrictor agent was measured by the provocative concentration required to produce a $20 \%$ fall $\left(\mathrm{PC}_{20}\right)$ in forced expired volume in one second $\left(\mathrm{FEV}_{1}\right)$.

All 14 asthmatics, 10 subjects with allergic rhinitis and none of the healthy controls were hyperresponsive to AMP. Subjects with allergic rhinitis had higher prevalence of hyperresponsiveness to AMP than healthy controls $(p=0.038)$. Although the prevalence of hyperresponsiveness for methacholine and for AMP in subjects with allergic rhinitis was similar (39\% and 36\%, respectively), four subjects had hyperresponsiveness to methacholine but not to AMP, whereas three subjects had hyperresponsiveness to AMP but not to methacholine.

To conclude, inhaled adenosine $5^{\prime}$-monophosphate causes airway narrowing in a significantly higher proportion of subjects with allergic rhinitis than healthy volunteers. Furthermore, methacholine and adenosine $5^{\prime}$-monophosphate hyperresponsiveness are not detected in the same individuals with allergic rhinitis, thus suggesting that responsiveness to the two bronchoconstrictor stimuli is not reflecting the same abnormalities of the airways.

Eur Respir J 2001; 17: 64-70.
\end{abstract}

Sección de Alergología and Universidad de Valencia, Valencia, Spain (The NAOMI project).

Correspondence: L. Prieto

Sección de Alergología

Hospital Dr. Peset

C/ Gaspar Aguilar 90

46017 Valencia

Spain

Fax: 34963862501

Keywords: Adenosine 5'-monophosphate airway responsiveness

allergic rhinitis

asthma

methacholine

Received: December 301999

Accepted after revision August 42000
Airway hyperresponsiveness can be defined as an increase above normal in both the ease and magnitude of airway narrowing on exposure to a number of nonsensitizing bronchoconstrictive stimuli [1]. Responsiveness can be assessed by inhalation of a direct stimulus, which causes airway smooth muscle contraction via stimulation of its receptors, and by inhalation of an indirect stimulus, resulting in smooth muscle contraction via activation of neural pathways or release of inflammatory mediators. Methacholine- and histamine-induced bronchoconstriction are likely to be due to a direct effect of these agonists on specific receptors on the airway smooth muscle. In contrast, the bronchoconstriction caused by inhalation of adenosine 5'-monophosphate (AMP), appears to be largely due to histamine release from primed airway mast cells [2]. Although airway responsiveness is usually measured with histamine and methacholine challenges [3], bronchial response to inhaled AMP has also been used to assess airway responsiveness [4-6]. In children, AMP challenge differentiates asthma from other chronic lung diseases, since this test is more specific for asthma than is a methacholine challenge [7].

It is now clear from a number of reports that nonasthmatic subjects with allergic rhinitis have a degree of airway responsiveness to direct bronchoconstrictor agents (histamine or methacholine), intermediate between that of healthy nonatopic persons and that of asthmatics [3, 8-10]. However, only a few data are available upon airway responsiveness to inhaled AMP in such patients $[6,11]$. In a small group of 10 atopic nonasthmatic subjects (some with allergic rhinitis), PHILLIPs et al. [11] have reported that inhaled AMP provokes bronchoconstriction of rapid onset. The present authors are not aware of any other studies examining the bronchoconstrictor response to aerosolised AMP in patients with allergic rhinitis, and the objective of the study was to examine the effect of inhaled AMP on lung function in subjects with allergic rhinitis. Therefore, AMP and methacholine inhalation provocation tests were performed in nonasthmatic subjects with allergic rhinitis, and the results compared with those obtained from asthmatics and healthy subjects.

\section{Methods}

\section{Subjects}

Fifty-two adult subjects were studied (14 asthmatics, 28 subjects with allergic rhinitis and 10 normal 
volunteers). Subjects with asthma and nonasthmatic patients with allergic rhinitis were recruited from our outpatient clinic, whereas healthy subjects were recruited from volunteers in the authors institution and students. Asthmatics and subjects with allergic rhinitis were selected to include a similar number of subjects sensitized to perennial and seasonal allergens. All 52 subjects were life-long nonsmokers, and none had history of chronic bronchitis, emphysema or respiratory tract infections during the four weeks before the study. Each subject was required to have a forced expired volume in one second (FEV1) of at least $80 \%$ of the predicted value. Current or exsmokers, pregnant women, and patients with significant renal, hepatic or cardiovascular disease were specifically excluded. Written informed consent was obtained from each patient and the study was approved by a local Ethics Committee.

Subjects with allergic rhinitis. These were defined as those individuals with a characteristic history of perennial or seasonal allergic rhinitis (rhinorrea, sneezing, obstruction and pruritus) and who also had skin sensitization to perennial or seasonal allergens. No subject had a present or past history of asthma (wheezing, dyspnoea, chest tightness, chronic cough, or exercise wheeze).

Diagnosis of asthma. This was performed according to the American Thoracic Society criteria [12]. Asthmatic subjects were defined as those individuals with a characteristic asthmatic history (recurrent attacks of reversible dyspnoea with wheezing) and who also had an increase in FEV1, of at least $15 \%$ after inhalation of $200 \mu \mathrm{g}$ of salbutamol, or a positive methacholine challenge test, defined as the provocative concentration required to produce a $20 \%$ fall in FEV1, $(\mathrm{PC} 20) \leqslant 8 \mathrm{mg} \cdot \mathrm{mL}^{-1}[3]$. All patients had mild asthma [13] and none were receiving any regular medication for asthma other than occasional short acting inhaled $\beta_{2}$-agonists, and in such cases, these were withheld for $8 \mathrm{~h}$ prior to each challenge. All 14 subjects were skin prick test (SPT) positive to one or more airborne allergens.

Healthy subjects. These had no history of asthma, allergic rhinitis, atopic eczema or other relevant disease, and were receiving no medication. Two were atopic as defined by a skin wheel response $>3 \mathrm{~mm}$ to at least one allergen.

Study design. Asthmatic and allergic rhinitis subjects with only seasonal symptoms were studied during a period of natural pollen exposure (May-July), whereas those with perennial symptoms were studied during a period of maximal exposure to mites (October-December). Subjects attended the laboratory on three visits at the same time of day. On the first day all subjects were evaluated for suitability and spirometry was performed. On each of the next two days, concentration-response studies with either methacholine or AMP (at least seven but no more than 11 days apart) were performed in a single-blind fashion. In all subjects the methacholine challenge test was performed first and baseline FEV1 varied by $<10 \%$.

\section{Methods}

Pulmonary function. Spirometry was performed with a calibrated dry rolling seal spirometer (2130, Sensormedics Co., Yorba Linda, CA, USA) according to standardized guidelines [14]. Baseline FEV1 and forced vital capacity were measured until three reproducible recordings, differing less than $5 \%$ were obtained. Highest values were used for analyses. Reference values were those of the European Community for Coal and Steel [15].

Skin prick test. In asthmatics and subjects with allergic rhinitis, atopic status was measured by SPTs using 13 common allergens applied to the forearm. The allergens (ALK-Abelló, Madrid, Spain) tested were house dust mites (Dermatophagoides pteronyssinus and Dermatophagoides farinae), household pets (cat and dog), pollens (mixed grass, olive, parietaria judaica, platanus orientalis, mixed weed), and moulds (Alternaria alternata, Aspergillus fumigatus, Cladosporium and Penicillium). Histamine and glycerinated saline were used as positive and negative controls. In healthy subjects, SPTs were performed with the six most common aeroallergens found in the Valencia area (D. pteronyssinus, mixed grass, olive, parietaria judaica and cat and dog dander). After $20 \mathrm{~min}$, wheal size was recorded as the long axis and its perpendicular. A skin-test response was regarded as positive if the wheal was $3 \mathrm{~mm}$ greater in diameter than that of the glycerinated saline.

Inhalation challenge tests. Inhalation provocation tests were performed according to a 2 min tidal breathing method [3]. Subjects were instructed to withhold their treatment for at least $8 \mathrm{~h}$ (inhaled short-acting, $\beta_{2-}$ agonists), 4 weeks (nasal topical corticosteroids and nasal topical cromoglycate) and 3 days (antihistamines) prior to each challenge.

Solutions of methacholine (acetyl- $\beta$-methylcholine chloride) and AMP (Sigma Chemical Co., St. Louis, MO, USA) were prepared in a $0.9 \%$ sodium chloride solution and were administered at room temperature as aerosols generated from a starting volume of $2 \mathrm{~mL}$ in a Hudson 1720 nebulizer (Temecula, CA, USA). Nebuliser output was $0.16 \pm 0.03 \mathrm{~mL} \cdot \mathrm{min}^{-1}$. The first nebulization administered in each challenge was normal saline. The postsaline FEV1, was used as the baseline for the calculation of subsequent percentage fall in FEV1. Thereafter, doubling concentrations of methacholine chloride or AMP were inhaled. Due to the effect of a deep inspiration on subsequent airway tone [16], only one measurement for FEV 1 was performed 60 to $90 \mathrm{~s}$ after inhalation of each concentration, unless the forced expiratory manoeuvre was judged to be technically unsatisfactory. The starting concentrations of methacholine were $0.39 \mathrm{mg} \cdot \mathrm{mL}^{-1}\left(2.0 \mathrm{mmol} \cdot \mathrm{L}^{-1}\right)$ for healthy subjects or patients with allergic rhinitis, and $0.095 \mathrm{mg} \cdot \mathrm{mL}^{-1}\left(0.5 \mathrm{mmol} \cdot \mathrm{L}^{-1}\right)$ for asthmatic patients. The starting concentrations of AMP were $1.56 \mathrm{mg} \cdot \mathrm{mL}^{-1}$ 
$\left(4.5 \mathrm{mmol} \cdot \mathrm{L}^{-1}\right)$ for healthy subjects or patients with allergic rhinitis, and $0.39 \mathrm{mg} \cdot \mathrm{mL}^{-1}\left(1.1 \mathrm{mmol} \cdot \mathrm{L}^{-1}\right)$ for asthmatic patients. The test was interrupted when FEV1 dropped by $>20 \%$ or when the highest concentration $\left(200 \mathrm{mg} \cdot \mathrm{mL}^{-1}\left(1022.0 \mathrm{mmol} \cdot \mathrm{L}^{-1}\right)\right.$ for methacholine and $400 \mathrm{mg} \cdot \mathrm{mL}^{-1}\left(1152.1 \mathrm{mmol} \cdot \mathrm{L}^{-1}\right)$ for AMP) had been administered. Two inhalations of salbutamol $(200 \mu \mathrm{g})$ from a metered-dose inhaler were then administered to each subject, and the FEV1 was measured 15 min later.

Data analysis. All summary statistics are expressed as means \pm SEM except for PC20 values. A concentrationresponse curve was obtained from each challenge by plotting the percentage change in FEV1, from the postsaline value against the logarithm of the agonist concentration. From this curve, the methacholine or AMP PC20 was read. A methacholine $\mathrm{PC}_{20}$ value of $200 \mathrm{mg} \cdot \mathrm{mL}^{-1}$ was assigned to six patients with allergic rhinitis and to seven healthy subjects in whom FEV1 dropped $<20 \%$ even when the highest concentration of methacholine was used. Further, a PC20 value for AMP could not be calculated in 18 subjects with allergic rhinitis and 10 healthy subjects. On these occasions the $\mathrm{PC}_{20}$ value was censored to the highest concentration of AMP given $\left(400 \mathrm{mg} \cdot \mathrm{mL}^{-1}\right)$. The potency of AMP in relation to that of methacholine was determined as the ratio of their respective $\mathrm{PC}_{20}$ values in $\mathrm{mmol} \cdot \mathrm{L}^{-1}$.

Statistical analyses were performed using SPSS for windows (release 6.01; SPSS Inc., Chicago, IL, USA). To evaluate normality of distributions the Kolmogorov-Smirnov test was used. The distributions of the PC20 values could not be normalized after logarithmic transformation and were analysed by nonparametric methods (Kruskal-Wallis test). When this was significant, each pairing was examined by means of the Mann-Whitney U-test. The distributions of all other variables were not significantly different from a standard normal distribution; hence, parametric tests (t-tests and one-way analysis of variance) were applied. Categorical variables were analysed with the Fisher's exact test. The relationship between the airway responses to methacholine and AMP was calculated using Spearman correlation coeffficients. A $p<0.05$ value was accepted as the minimum level of statistical significance.

\section{Results}

The clinical and pulmonary function data at baseline for asthmatics, subjects with allergic rhinitis and healthy volunteers are presented in table 1 . The three groups did not differ with respect to age and sex. Moreover, asthmatic and allergic rhinitis patients did not differ with respect to duration of symptoms and prevalence of skin sensitization to perennial or seasonal allergens. The mean lung function value (FEV1/FVC $\%$ ) for the group with asthma was significantly lower than the mean value for the allergic rhinitis subjects $(p=0.004)$ and the healthy individuals $(p=0.003)$, but there were no significant differences between subjects with allergic rhinitis and healthy volunteers. Mean baseline FEV1 values were not significantly different within the three groups before the two different provocation tests (table 2).

\section{Methacholine provocation}

All 14 asthmatics and 11 of 28 subjects with allergic rhinitis were hyperresponsive $\left(\mathrm{PC} 20 \leqslant 8 \mathrm{mg} \cdot \mathrm{mL}^{-1}\right)$, whereas none of the healthy controls had methacholine hyperresponsiveness. The proportion of subjects with airway hyperresponsiveness to methacholine was higher $(p=0.037)$ in subjects with allergic rhinitis than in healthy controls.

The PC20 methacholine values (table 2, fig. 1) in the asthma group were significantly lower $(\mathrm{p}<0.001)$ than in either the allergic rhinitis group or healthy control group. The PC20 methacholine values in the allergic rhinitis group were also significantly lower than in the healthy control group $(\mathrm{p}=0.002)$. The methacholine provocation was continued up to a concentration of $200 \mathrm{mg} \cdot \mathrm{mL}^{-1}$, but seven of the 10 control subjects did not respond to the highest concentration administered.

\section{Adenosine 5'-monophosphate provocation}

All 14 asthmatics and 10 of 28 subjects with allergic rhinitis were hyperresponsive $\left(\mathrm{PC}_{20} \leqslant 400 \mathrm{mg} \cdot \mathrm{mL}^{-1}\right)$, whereas none of the healthy controls had AMP hyperresponsiveness. The proportion of subjects with airway hyperresponsiveness to AMP was higher $(p<0.001)$ in asthmatics than in either subjects with allergic rhinitis or healthy controls. Subjects with allergic rhinitis also had a higher prevalence of hyperresponsiveness to AMP than healthy controls $(\mathrm{p}=0.038)$.

The PC20 AMP values (table 2, fig. 2) in the asthma group were significantly lower $(\mathrm{p}<0.001)$ than in either the allergic rhinitis group or healthy control group. Although the PC20 AMP values in the allergic rhinitis group were lower than in the healthy control group, this difference was not statistically significant $(\mathrm{p}=0.10)$. In the allergic rhinitis group 18 of the 28 subjects did not respond to the highest AMP concentration. Furthermore, none of the healthy subjects experienced a $20 \%$ fall in FEV1, when the highest concentration of AMP was administered.

Table 1. - Subject characteristics

\begin{tabular}{lccc}
\hline & Asthma & $\begin{array}{c}\text { Allergic } \\
\text { rhinitis }\end{array}$ & Healthy \\
\hline $\begin{array}{l}\text { Subjects n } \\
\text { Age yrs }\end{array}$ & 14 & 28 & 10 \\
Male/Female & $34.3 \pm 3.2$ & $30.9 \pm 1.8$ & $37.2 \pm 3.9$ \\
Duration of & $12.6 \pm 2.9$ & $17 / 11$ & $3 / 7$ \\
symptoms yrs & & $7.6 \pm 1.1$ & - \\
Perennial/seasonal & $9 / 5$ & $16 / 12$ & - \\
FEV1 \% pred & $104.9 \pm 3.2$ & $107.4 \pm 1.5$ & $111.8 \pm 1.2$ \\
FEV1/FVC \% & $79.8 \pm 1.6$ & $85.3 \pm 1.0$ & $87.1 \pm 1.2$ \\
\hline
\end{tabular}

Data are presented as mean \pm SEM. FEV1: forced expiratory volume in one second; FVC: forced vital capacity. 
Table 2. - Prechallenge forced expired volume in one second (FEV 1$)$ and airway responsiveness to methacholine and adenosine $5^{\prime}$-monophosphate (AMP) in the three groups

\begin{tabular}{lccc}
\hline & Asthma & Allergic rhinitis & Healthy \\
\hline Prechallenge FEV1 & & & \\
Methacholine & $3.42 \pm 0.27$ & $3.96 \pm 0.20$ & $3.12 \pm 0.19$ \\
AMP & $3.41 \pm 0.26$ & $3.96 \pm 0.19$ & $3.10 \pm 0.18$ \\
PC20 mg.mL & & $75.5(1.1-200.0)$ & $123.0(11.9-200.0)$ \\
Methacholine* & $0.4(0.1-1.5)$ & $169.8(6.0-400.0)$ & 400.0 \\
AMP* & $11.7(1.1-133.6)$ & \\
\hline
\end{tabular}

Values are displayed as means \pm SEM. *: Data presented as geometric mean (and range). PC20: provocative concentration of agonist required to produce a $20 \%$ fall in FEV 1 .

Relationship between airway responsiveness to methacholine and adenosine 5'-monophosphate

Although the prevalence of hyperresponsiveness for methacholine and for AMP in the three groups was similar, four of the allergic rhinitis patients with methacholine hyperresponsiveness had a fall in FEV1 of $<20 \%$ after the maximal concentration of AMP, whereas three allergic rhinitis subjects with hyperresponsiveness to AMP had methacholine PC20 values $>8 \mathrm{mg} \cdot \mathrm{mL}^{-1}$. Thus, AMP and methacholine challenges do not always identify the same individuals with allergic rhinitis.

The $\mathrm{PC} 20$ methacholine in asthmatics ranged 0.5 $7.7 \mathrm{mmol} \cdot \mathrm{L}^{-1}$ with a geometric mean of $2.0 \mathrm{mmol} \cdot \mathrm{L}^{-1}$, whereas the PC20 AMP ranged $3.2-384.8 \mathrm{mmol} \cdot \mathrm{L}^{-1}$ with a geometric mean of $33.7 \mathrm{mmo} \cdot \mathrm{L}^{-1}$, suggesting that AMP is around 17 times less potent than methacholine as a bronchoconstrictor in asthma on a molar basis.

The PC20 methacholine in subjects with allergic rhinitis ranged $5.6-1022.0 \mathrm{mmol} \cdot \mathrm{L}^{-1}$ with a geometric mean of $385.8 \mathrm{mmol} \cdot \mathrm{L}^{-1}$, whereas the PC20 AMP ranged $17.3-1152.1 \mathrm{mmol} \cdot \mathrm{L}^{-1}$ with a geometric mean of $489.1 \mathrm{mmol} \cdot \mathrm{L}^{-1}$. With the reservation that a censored value was assigned to nonresponders to AMP and methacholine, AMP was 1.3-fold less potent than methacholine in causing bronchoconstriction in subjects with allergic rhinitis.

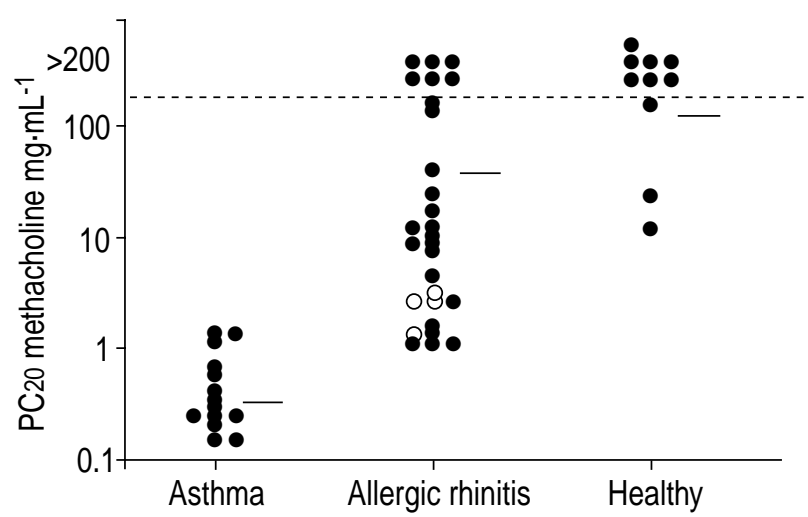

Fig. 1. - Provocative concentration causing a $20 \%$ fall in forced expired volume in one second (PC20) methacholine values in the three groups. $\bigcirc$ : subjects with airway hyperresponsiveness to methacholine but not to adenosine $5^{\prime}$-monophosphate (AMP); horizontal lines: geometric means. Values above dashed line $\left(>200 \mathrm{mg} \cdot \mathrm{mL}^{-1}\right)$ are censored.
A significant correlation was found between methacholine and AMP PC20 values in asthmatics $(p=0.69$, $p=0.02)$, in the overall group of subjects with allergic rhinitis ( $p=0.61, p=0.001$, fig. 3 ), and in the 22 allergic rhinitis subjects with no censored values for methacholine $(\mathrm{p}=0.54, \mathrm{p}=0.01)$.

\section{Discussion}

The results of the present study indicate that inhaled AMP causes airway narrowing in a significantly higher proportion of nonasthmatic subjects with allergic rhinitis than healthy controls. The results also show that although methacholine and AMP responsiveness are significantly related, the two bronchoconstrictor agents do not always identify the same individuals with allergic rhinitis. These findings suggest that methacholine and AMP challenges identify different abnormalities of the airways in subjects with allergic rhinitis.

It is unlikely that the data was influenced by methodological errors. Firstly, there were no significant differences between the baseline airway caliber prior to bronchial challenges on any of the study days. Thus, effects caused by differing baseline airway caliber on the subsequent determination of $\mathrm{PC} 20$ could be eliminated. In addition, challenges were carried out at the same time of the day, thus ruling out a possible influence of circadian variations on airway responsiveness.

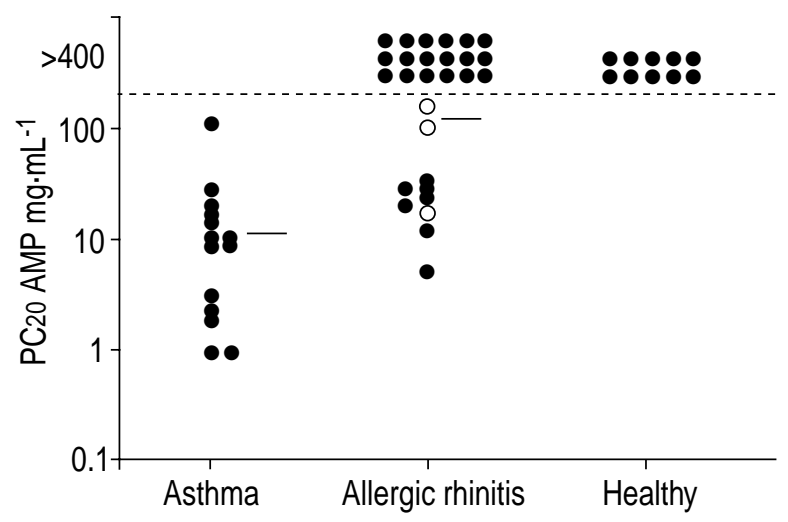

Fig. 2. - Provocative concentration causing a $20 \%$ fall in forced expired volume in one second ( $\mathrm{PC}_{20}$ ), adenosine $5^{\prime}$-monophosphate values in the three groups. $\bigcirc$ : subjects with airway hyperresponsiveness to adenosine $5^{\prime}$-monophosphate (AMP) but not to methacholine; horizontal lines: geometric means. Values above dashed line $\left(>400 \mathrm{mg} \cdot \mathrm{mL}^{-1}\right)$ are censored. 


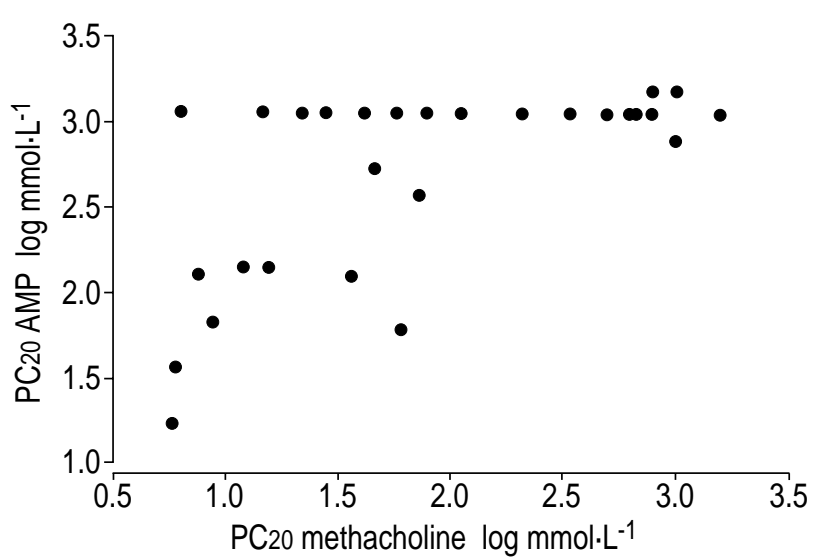

Fig. 3. - Correlation between provocative concentration causing a $20 \%$ fall in forced expired volume in one second (PC20) methacholine and $\mathrm{PC}_{20}$ adenosine $5^{\prime}$-monophosphate (AMP) in subjects with allergic rhinitis. A significant correlation was found in the overall group $(\rho=0.61, p=0.001)$ and in the 22 subjects with no censored values for methacholine $(\rho=0.54, p=0.01)$.

Secondly, inhalation challenges were not performed randomly and there is a slight possibility that the methacholine challenge might have influenced the AMP test. However, because the study days were separated by 7 to 11 days, it is highly unlikely that there was any carryover effect. Furthermore, the protocol was identical for the different groups of subjects and therefore, if there was any effect of one challenge on the response of the other, it would be the same in the three groups. Thirdly, none of the subjects was being treated with medications that could have affected the response to bronchoconstrictor agents. Moreover, by subjecting each volunteer to all provocations, it was possible to make a direct comparison of the potencies and effects of each agonist in the same subject. Finally, in a recent study the response to AMP in asthmatic subjects was reasonably repeatable and similar to the repeatability found for bronchoprovocation with histamine [17].

There were some important methodological problems in this study. Estimation of the airway responsiveness was complicated because six $(21 \%)$ patients with allergic rhinitis and seven $(70 \%)$ healthy subjects had PC20 methacholine values above the upper limit of measurement. In addition, $18(64 \%)$ patients with allergic rhinitis and $10(100 \%)$ healthy controls had PC20 AMP values above the upper limit of measurement. A PC20 value of $200 \mathrm{mg} \cdot \mathrm{mL}^{-1}$ for methacholine and $400 \mathrm{mg} \cdot \mathrm{mL}^{-1}$ for AMP was assigned to these subjects, but this gives an underestimation of their true PC20, value. Given these restrictions, the significance of the differences in the responses of the various groups is almost certainly an underestimation.

It is now clear from a number of studies that an increased responsiveness to direct bronchoconstrictor agents, such as histamine or methacholine, is a common feature in subjects with allergic rhinitis [3, 8-10, 18]. In addition several reports have indicated that subjects with allergic rhinitis have a degree of airway sensitivity to inhaled methacholine intermediate between that of healthy nonatopic persons and that of asthmatics [3, 8-10], confirmed by the current findings.

The present study has found a prevalence of $36 \%$ for airway hyperresponsiveness to AMP among subjects with allergic rhinitis. In addition, subjects with allergic rhinitis were found to have values for the prevalence of AMP hyperresponsiveness that were intermediate between those detected in normal subjects and mild asthmatics. There is convincing evidence that, in sensitized subjects with asthma $[19,20]$ or allergic rhinitis $[21,22]$, natural allergen exposure during a pollen season results in increased methacholine responsiveness. In addition, airway responsiveness to inhaled AMP increases during periods of natural allergen exposure in asthmatics [23]. but no information is available in subjects with allergic rhinitis. Pollensensitive subjects in the present study were tested during a period of natural pollen exposure and this may explain the high prevalence of hyperresponsiveness in the subjects with allergic rhinitis.

At the time of writing, there have been only two published studies $[6,11]$ on airway responsiveness to inhaled AMP in atopic nonasthmatic subjects (some with allergic rhinitis). PHILLIPS et al. [11] measured airway responsiveness to AMP in 10 atopic nonasthmatic subjects. In this study seven subjects $(70 \%)$ had a PC20 value $\leqslant 400 \mathrm{mg} \cdot \mathrm{mL}^{-1}$. There are several possible explanations for this apparent contradiction. In the study by PHILliPs et al. [11], the nebulizer output was $0.48 \mathrm{~mL} \cdot \mathrm{min}^{-1}$ and subjects inhaled the aerosolized solutions in five consecutive breaths from end tidal volume to full inspiratory capacity. In contrast, the nebulizer used in the present study had an output of $0.16 \mathrm{~mL} \cdot \mathrm{min}^{-1}$ and subjects inhaled the aerosol by tidal breathing for two minutes. Furthermore, it is important to emphasize that subjects in the study by PHLLIPS et al. [11] were not selected on the presence of allergic rhinitis, but on the basis of the presence of atopy. In another study from the same group, the prevalence of airway hyperresponsiveness to inhaled AMP in allergic patients without asthma was 59\% when responsiveness was expressed as the concentration of agonist required to produce a fall of $35 \%$ in specific airway conductance [6]. Furthermore, the sensitivity (PC35 value) to AMP provocation was increased in allergic patients without asthma when compared with nonatopic normal controls [6]. In contrast, airway sensitivity (PC20 value) to AMP was similar in the present study's allergic rhinitis patients and healthy controls. The authors presume, pending further data, that this finding is a consequence of the high proportion of subjects with censored values in each group.

A cut-off point of $400 \mathrm{mg} \cdot \mathrm{mL}^{-1}$ separating normal from increased bronchial responsiveness to AMP may appear arbitrary. However, previous reports have found that asthmatic subjects generally had a fall in FEV $1 \geqslant 20 \%$ after inhalation of AMP in concentrations up to $400 \mathrm{mg} \cdot \mathrm{mL}^{-1}$, while most healthy subjects showed a $\mathrm{PC}_{20}$ above this value $[7,24]$. By this reason, a $\mathrm{PC}_{20}$ AMP $\leqslant 400 \mathrm{mg} \cdot \mathrm{mL}^{-1}$ has been chosen as the criteria for increased responsiveness to this bronchoconstrictor agent.

In keeping with previous reports [25], the present authors have detected that inhaled AMP was, on 
average, 17 times less potent than methacholine in constricting the airways of asthmatic patients. In contrast, with the reservation that a censored value was assigned to nonresponders to AMP and methacholine, AMP was only 1.3 times less potent than methacholine in constricting the airways of subjects with allergic rhinitis. In this last group of subjects, there was a significant relationship between the AMP and methacholine concentrations required to produce equivalent bronchoconstriction.

Another important finding in this study was that airway hyperresponsiveness to methacholine is not necessarily accompanied by hyperresponsiveness to AMP in patients with allergic rhinitis. Four subjects with a positive methacholine challenge failed to respond to AMP. Moreover, three of the 10 allergic rhinitis patients with a positive AMP challenge failed to respond to methacholine. Thus, methacholine and AMP challenges do not always identify the same individuals. These results suggest that methacholine and AMP hyperresponsiveness are not reflecting the same abnormalities of the airways.

The evidence that inhaled AMP acts through pathways involved in asthmatic inflammation [26] may help explain the clinical relevance of the findings of this study. The present results indicate that airway hyperresponsiveness to methacholine and AMP is not detected in the same nonasthmatic subjects with allergic rhinitis, and several reports have shown that subjects with allergic rhinitis may have inflammatory changes in the airways that are intermediate when compared with that in clinically active asthma and the normal nonatopic state [27-29]. Moreover, inflammatory changes within the lower airways are detected predominantly, but not exclusively, in patients with allergic rhinitis and airway hyperresponsiveness to methacholine [28, 29]. If bronchoconstriction induced by AMP depends, at least in part, on the state of activation of airway mast cells [30-32], it is interesting to speculate that AMP responsiveness may be a more direct marker of allergic airway inflammation in subjects with allergic rhinitis than direct bronchoconstrictors such as histamine or methacholine. In line with these speculations, PoLOSA et al. [24] have recently demonstrated that in nonasthmatic subjects with allergic rhinitis, airway responsiveness to AMP is more strongly related to sputum eosinophilia than is that to methacholine.

Conversely, it is tempting to speculate that in subjects with allergic rhinitis, the presence of methacholine hyperresponsiveness might be an indication of increased susceptibility to the development of asthma, but only a few and conflicting data are available. BRAMAN $e t$ al. [18] have reported that subjects with seasonal allergic rhinitis and methacholine hyperresponsiveness are at greater risk for asthma than those with normal responsiveness. However, this study could not be confirmed by data from a four-year follow-up in 66 patients with perennial or seasonal allergic rhinitis [33]. Further prospective studies are needed to clarify the prognostic value of AMP hyperresponsiveness in subjects with allergic rhinitis.

In conclusion, this study demonstrates that a significant proportion of subjects with allergic rhinitis responded with airway narrowing upon adenosine 5'- monophosphate provocation. Methacholine and adenosine $5^{\prime}$-monophosphate hyperresponsiveness was not detected in the same individuals with allergic rhinitis, thus suggesting that responsiveness to the two bronchoconstrictor agents is not reflecting the same abnormalities of the airways. These findings suggest that the airway response to adenosine $5^{\prime}$-monophosphate may provide a useful tool to explore further the relationship between allergic rhinitis and asthma.

\begin{abstract}
Acknowledgements. The authors thank B. Camps and R. Rojas for their technical assistance, and Laboratorios Bial-Aristegui (Bilbao, Spain) for their help and collaboration during the study.
\end{abstract}

\section{References}

1. Woolcock AJ. What is bronchial hyperresponsiveness from the clinical standpoint? In: Page CP, Gardiner PJ, eds. Airway hyperresponsiveness: is it really important for asthma? Oxford: Blackwell Scientific Publications. 1993; pp. 1-9.

2. Cushley MJ, Holgate ST. Adenosine-induced bronchoconstriction in asthma: role of mast cell-mediator release. J Allergy Clin Immunol 1985; 75: 272-278.

3. Cockcroft DW, Killian DN, Mellon JJA, Hargreave FE. Bronchial reactivity to inhaled histamine: a method and clinical survey. Clin Allergy 1977; 7: 235-243.

4. Mann JS, Holgate ST, Renwick AG, Cushley MJ. Airway effect of purine nucleosides and nucleotides and release with bronchial provocation in asthma. J Appl Physiol 1986; 61: 1667-1676.

5. Cushley MJ, Tattersfield AK, Holgate ST. Inhaled adenosine and guanosine on airway resistance in normal and asthmatic subjects. Br J Clin Pharmacol 1983; 15: 161-165.

6. Church MK, Featherstone RL, Cushley MJ, Mann JS, Holgate ST. Relationships between adenosine, cyclic nucleotides, and xantines in asthma. J Allergy Clin Immunol 1986; 78: 670-675.

7. Avital A, Springer Ch, Bar-Yishay E, Godfrey S. Adenosine, methacholine, and exercise challenges in children with asthma or paediatric chronic obstructive pulmonary disease. Thorax 1995; 50: 511-516.

8. Stevens WJ, Vermeire PA. Bronchial responsiveness to histamine and allergen in patients with asthma, rhinitis, cough. Eur J Respir Dis 1980; 61: 203-212.

9. Prieto L, Gutiérrez V, Bertó JM, Camps B. Sensitivity and maximal response to methacholine in perennial and seasonal allergic rhinitis. Clin Exp Allergy 1996; 26: 61-67.

10. Prieto L, Gutiérrez V, Morales C, Marín J. Differences in sensitivity, maximal response and position of the concentration-response curve to methacholine between asthmatics, patients with allergic rhinitis and healthy subjects. Respir Med 1998; 92: 88-94.

11. Phillips GD, Ng WH, Church MK, Holgate ST. The response of plasma histamine to bronchoprovocation with methacholine, adenosine-5' monophosphate, and allergen in atopic nonasthmatic subjects. Am Rev Respir Dis 1990; 141: 9-13. 
12. American Thoracic Society. Standards for the diagnosis and care of patients with chronic obstructive pulmonary disease (COPD) and asthma. Am Rev Respir Dis 1987; 136: 225-244.

13. National Heart, Lung and Blood Institute. Guidelines for the diagnosis and management of asthma. NIH Publication No. 97-4051. 1997.

14. American Thoracic Society. Standardization of spirometry-1987 update. Am Rev Respir Dis 1987; 136: 1285-1294.

15. Quanjer $\mathrm{PH}$, ed. Standardized lung function testing. Bull Eur Physiopathol Respir 1983; 19: Suppl. 5, 1-95.

16. Prieto L, Marin J. Methacholine inhalation challenge. Practical consequences of using duplicate spirogram after each concentration. Ann Allergy 1993; 70:487-490.

17. Egbagbe E, Pavord ID, Wilding P, Thompson-Coon $\mathrm{J}$, Tattersfield AK. Adenosine monophosphate and histamine induced bronchoconstriction: repeatability and protection by terbutaline. Thorax 1997; 52: 239 243.

18. Braman SS, Barrows AA, De Cotiis BA, Settipane GA, Corrao WM. Airway hyperresponsiveness in allergic rhinitis. A risk factor for asthma. Chest 1987; 91: 671-674.

19. Boulet LP, Cartier A, Thomson NC, Roberts RS, Dolovich J, Hargreave FE. Asthma and increases in nonallergic bronchial responsiveness from seasonal pollen exposure. J Allergy Clin Immunol 1983; 71: 399 406.

20. Prieto L, Bertó JM, Lopez M, Peris A. Modifications of PC20 and maximal degree of airway narrowing to methacholine after pollen season in pollen sensitive asthmatic patients. Clin Exp Allergy 1993; 23: 172-178.

21. Boulet LP, Morin D, Milot J, Turcotte H. Bronchial responsiveness increases after seasonal antigen exposure in non-asthmatic subjects with pollen-induced rhinitis. Ann Allergy 1989; 63: 114-119.

22. Prieto L, López M, Bertó JM, Peris A. Modification of concentration response curves to inhaled methacholine after the pollen season in subjects with pollen induced rhinitis. Thorax 1994; 49: 711-713.

23. Van Veizen E, van den Bos JW, Benckhuijsen JAW, van Essel T, de Bruijn R, Aalbers R. Effect of allergen avoidance at high altitude on direct and indirect bronchial hyperresponsiveness and markers of inflam- mation in children with allergic asthma. Thorax 1996; 51: 582-584.

24. Polosa R, Ciamarra I, Mangano G, et al. Bronchial hyperresponsiveness and airway inflammation markers in nonasthmatics with allergic rhinitis. Eur Respir $J$ 2000; 15: 30-35.

25. Polosa R, Lau LCK, Holgate ST. Inhibition of adenosine $5^{\prime}$ monophosphate- and methacholine-induced bronchoconstriction in asthma by inhaled frusemide. Eur Respir J 1990; 3: 665-672.

26. Weersink EJM, Donma RR, Postma DS, Koëter GH. Fluticasone propionate, salmeterol xinafoate, and their combination in the treatment of nocturnal asthma. Am J Respir Crit Care Med 1997; 155: 1241-1246.

27. Djukanovic R, Lai CKW, Wilson JW, et al. Bronchial mucosal manifestations of atopy: a comparison of markers of inflammation between atopic asthmatics, atopic nonasthmatics and healthy controls. Eur Respir $J$ 1992; 5: 538-544.

28. Foresi A, Leone C, Pelucchi A, et al. Eosinophils, mast cells, and basophils in induced sputum from patients with seasonal allergic rhinitis and perennial asthma: relationship to methacholine responsiveness. J Allergy Clin Immunol 1997; 100: 58-64.

29. Gutiérrez V, Prieto L, Torres V, Morales C, González E. Peak flow variability and sputum eosinophilia in allergic rhinitis. Ann Allergy Asthma Immunol 1998; 81: 143-150.

30. Björck T, Gustafsson LE, Dahlen SE. Isolated bronchi from asthmatics are hyperresponsive to adenosine, which apparently acts indirectly by liberation of leukotrienes and histamine. Am Rev Respir Dis 1992; 145: 1087-1091.

31. Polosa R, Ng WH, Crimi N, Vancheri C, Holgate ST, Church MK, Mistreta D. Release of mast-cell-derived mediators after endobronchial adenosine challenge in asthma. Am J Respir Crit Care Med 1995; 151: 624 629.

32. Forsythe P, McGarvey LPA, Heaney LG, MacMahon $\mathrm{J}$, Ennis M. Adenosine induces histamine release from human bronchoalveolar lavage mast cells. Clin Sci 1999; 96: 349-355.

33. Prieto L, Berto JM, Gutiérrez V. Airway responsiveness to methacholine and risk of asthma in patients with allergic rhinitis. Ann Allergy 1994; 72: 354-358. 